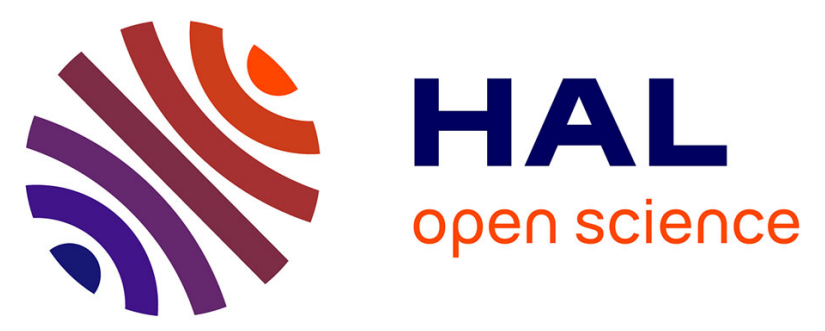

\title{
A new method to calculate external mechanical work using force-platform data in ecological situations in humans: Application to Parkinson's disease
}

Vincent Gigot, Virginie van Wymelbeke, Davy Laroche, Thomas Mouillot, Agnès Jacquin-Piques, Matthieu Rossé, Michel Tavan, Laurent Brondel

\section{To cite this version:}

Vincent Gigot, Virginie van Wymelbeke, Davy Laroche, Thomas Mouillot, Agnès Jacquin-Piques, et al.. A new method to calculate external mechanical work using force-platform data in ecological situations in humans: Application to Parkinson's disease. Gait \& Posture, 2016, 48, pp.202-208. 10.1016/j.gaitpost.2016.04.013 . hal-01386926

\section{HAL Id: hal-01386926 https://u-bourgogne.hal.science/hal-01386926}

Submitted on 26 Sep 2017

HAL is a multi-disciplinary open access archive for the deposit and dissemination of scientific research documents, whether they are published or not. The documents may come from teaching and research institutions in France or abroad, or from public or private research centers.
L'archive ouverte pluridisciplinaire HAL, est destinée au dépôt et à la diffusion de documents scientifiques de niveau recherche, publiés ou non, émanant des établissements d'enseignement et de recherche français ou étrangers, des laboratoires publics ou privés. 


\title{
A new method to calculate external mechanical work using force-platform data in ecological situations in humans: Application to Parkinson's disease
}

\author{
Vincent Gigot ${ }^{a}$, Virginie Van Wymelbeke ${ }^{b}$, Davy Laroche ${ }^{c}$, Thomas Mouillot ${ }^{a}$, \\ Agnès Jacquin-Piques ${ }^{\mathrm{a}, \mathrm{d}}$, Matthieu Rossé ${ }^{\mathrm{e}}$, Michel Tavan ${ }^{\mathrm{a}}$, Laurent Brondel ${ }^{\mathrm{a}, \mathrm{f}, *}$ \\ ${ }^{\text {a }}$ Taste and Food Behavior Center (CSGA), UMR 6265 CNRS, UMR 1324 INRA, University of Burgundy, Dijon, France \\ ${ }^{\mathrm{b}}$ Department of Geriatrics, University Hospital of Dijon, Dijon, France \\ ${ }^{\mathrm{c}}$ Platform of Technology Investigation, INSERM CIC 1432, University Hospital of Dijon, Dijon, France ; INSERM U1093, University of Burgundy, Dijon, France \\ ${ }^{\mathrm{d}}$ Department of Clinical Neurophysiology, University Hospital of Dijon, Dijon, France \\ ${ }^{\mathrm{e}}$ Laboratory of Electronics, Information and Image (LE2I), UMR CNRS 5158, University of Burgundy, Dijon, France \\ ${ }^{\mathrm{f}}$ Department of Hepato-Gastroenterology, University Hospital of Dijon, Dijon, France
}

\section{A R T I C L E I N F O}

\section{Article history:}

Received 12 June 2015

Received in revised form 9 April 2016

Accepted 11 April 2016

\section{Keywords:}

Energy expenditure

External mechanical work

Human physical activity

Parkinson's disease

Work efficiency

\begin{abstract}
A B S T R A C T
Background and aim: To accurately quantify the cost of physical activity and to evaluate the different components of energy expenditure in humans, it is necessary to evaluate external mechanical work $\left(W_{\text {EXT }}\right)$. Large platform systems surpass other currently used techniques. Here, we describe a calculation method for force-platforms to calculate long-term $W_{\text {EXT }}$.

Methods: Each force-platform $(2.46 \times 1.60 \mathrm{~m}$ and $3.80 \times 2.48 \mathrm{~m})$ rests on 4 piezoelectric sensors. During long periods of recording, a drift in the speed of displacement of the center of mass (necessary to calculate $W_{\text {EXT }}$ ) is generated. To suppress this drift, wavelet decomposition is used to low-pass filter the source signal. By using wavelet decomposition coefficients, the source signal can be recovered. To check the validity of $W_{\mathrm{EXT}}$ calculations after signal processing, an oscillating pendulum system was first used; then, 10 healthy subjects performed a standardized exercise (squatting exercise). A medical application is also reported in eight Parkinsonian patients during the timed "get-up and go" test and compared with the same test in ten healthy subjects.

Results: Values of $W_{\text {EXT }}$ with the oscillating pendulum showed that the system was accurate and reliable. During the squatting exercise, the average measured $W_{\mathrm{EXT}}$ was $0.4 \%$ lower than theoretical work. $W_{\mathrm{EXT}}$ and mechanical work efficiency during the "get-up and go" test in Parkinson's disease patients in comparison with that of healthy subjects were very coherent.

Conclusions: This method has numerous applications for studying physical activity and mechanical work efficiency in physiological and pathological conditions.
\end{abstract}

(c) 2016 Elsevier B.V. All rights reserved.

\section{Introduction}

The measurement of energy expenditure (EE) linked to physical activity in humans may be useful to (1) analyze physiological processes, (2) broaden the understanding of energy imbalance mechanisms, (3) evaluate physical activity in numerous diseases

\footnotetext{
* Corresponding author at: Centre des Sciences du Goût et de l'Alimentation, $9^{\mathrm{E}}$ Bd Jeanne d'Arc, 21000 Dijon, France. Tel.: +33 (0) 3806816 77; fax: +33 (0) 380681601 .

E-mail address: laurent.brondel@u-bourgogne.fr (L. Brondel).
}

and, (4) adapt training programs in various postural disturbances [1-6]. Due to anthropological estimations and the unknown efficiency of physiological mechanisms, it is difficult to accurately quantify the mechanical work of physical activity, which could be calibrated exercise or everyday-life movements [7,8]. Mechanical efficiency is the key link between EE and external mechanical work $\left(W_{\text {EXT }}\right)$.

$W_{\text {ExT }}$ is defined as the product of the resultant of external forces applied to the body by the displacement of the center of mass (CoM) along the direction of each force component in the vertical and horizontal directions [9]. It can be calculated from recordings of the components using a multi-axis force-platform $[7,10]$. These 
components are integrated in the three dimensions of space to compute the velocity of the CoM for each dimension. Then, $W_{\mathrm{EXT}}$ is calculated by integrating the product of the forces by the CoM velocity over time.

Evaluations of the functional capacities of patients are performed with small $\left(\approx 1 \mathrm{~m}^{2}\right)$ platforms and during short $(\approx 10 \mathrm{~s})$ periods of time [10-18]. However, such functional capacities need to be evaluated in ecological situations. Large force-platforms allow the evaluation of daily living situations (longer periods of time, greater space of displacements). To the best of our knowledge, there are no reports of calculation methods for $W_{\text {EXT }}$ from long recordings and using large platforms, although some authors $[7,8,19,20]$ have reported the results of mechanical work in such situations. This lack of information is a setback for laboratories that want to calculate $W_{\text {EXT }}$.

In the present study, we established a signal processing protocol using wavelet decomposition to detect and remove the velocity drift problem that is observed during long measurement periods and then to calculate $W_{\text {EXT. }}$ Indeed, it is difficult to calculate $W_{\text {EXT }}$ because over long periods of measurement a drift appears in the integration for velocity calculations (the drift is due to the need to know the mass of the subject in real time). To verify the validity of the signal processing method, a mechanical pendulum was first tested on the platform and compared with a mathematical model. Then, healthy subjects performed calibrated physical exercises with simultaneous measurements of $W_{\text {EXT. }}$. Finally, $W_{\text {EXT }}$ and EE were evaluated in Parkinsonian patients and in healthy subjects during a timed "up and go" test (TUG) $[21,22]$.

\section{Materials and methods}

\subsection{Instrumentation}

Each floor of the two calorimetric chambers of the Center des Sciences du Goût et de l'Alimentation is composed of a force-platform $(2.46 \times 1.60 \mathrm{~m}$ and $3.80 \times 2.48 \mathrm{~m})$ resting on four three-dimensional piezoelectric sensors (type z12165, Kistler, Winterthur, Switzerland). The outputs of the homolog component forces of the four sensors are combined to give the resultant force vector in each dimension of space. An eight-channel amplifier (type 5117A, Kistler, Ostfildern Germany) allows the sensitivity of the system to be adjusted from $1 \times 10^{-3}$ to $9.99 \times 10^{+6} \mathrm{~N}^{-V^{-1}}$, which makes it possible to detect both weak and strong movements with an accuracy varying from \pm 1 to $\pm 3 \%$. Analog output voltages from the amplifier are recorded through a 16-bit resolution card with 32 differential inputs (DAQ PCI 6033E, National Instruments, Austin, TX, USA). The sampling frequencies, which depend on the duration of different applications, can be adjusted from 50 to $500 \mathrm{~Hz}$. The acquisition interphase, developed with Labview software (National

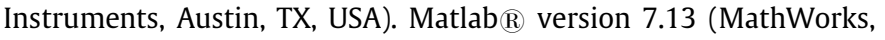
Natick, MA, USA), is used to calculate the mechanical parameters (velocities and $W_{\text {EXT }}$ ). It is possible to record data over periods ranging from less than one minute to $24 \mathrm{~h}$.

$\mathrm{W}_{\mathrm{EXT}}$ is calculated using the double integration technique as indicated by Lafond et al. [23]. Briefly, acceleration of the CoM is computed from force-platform components. Then its movement is reflected by the double integral of this acceleration. $W_{\mathrm{EXT}}$ is then computed from these components of CoM movements.

\subsection{Signal processing}

For recordings of less than $15 \mathrm{~s}$, velocities are easily calculated by integrating the ratio of the force function of time and body mass (respectively $F(t) / m$ ). However, for longer recordings, the velocity values drift. To overcome this non-linear drift, which can be regarded as low component frequency coupled with the force signal, a frequency analysis based on wavelet decomposition is used as recommended [24-28].

In practical terms, the decomposition and reconstruction work like successive band filters. The source signal is simultaneously filtered by low-pass and high-pass filters. Then, both signals are down-sampled by a factor of 2 . In the first decomposition level, the signal is divided into two parts, "approximation" coefficients containing low frequency information (cA1) and "detail" coefficients containing high frequency information, including noise (cD1). Thereafter, the decomposition process can be repeated with successive "approximations" where cA1 gives CA2 and CD2; CA2 gives CA3 and $\mathrm{CD} 3$; and so on. To reconstruct the source signal, inverse wavelet decomposition is performed by applying upsampling and then a mirror filter. This reconstruction is performed on all of the signal components to return to "approximations" and "details" and then to the source signal S. All level components are associated by summation as follows: $S=A 1+D 1$ or $\mathrm{S}=\mathrm{A} 2+\mathrm{D} 1+\mathrm{D} 2$ or $\mathrm{S}=\mathrm{A} 3+\mathrm{D} 1+\mathrm{D} 2+\mathrm{D} 3 \ldots$ The Matlab functions from the wavelet toolbox are used for the calculations (Matlab R2011B).

\subsection{Verification of $\mathrm{W}_{E X T}$ calculation method}

\subsubsection{Pendulum}

An oscillating pendulum system inserted inside a box-section framework $(1.10 \times 0.45 \times 1.12 \mathrm{~m})$ was used to verify the validity of $W_{\mathrm{EXT}}$ calculations. The oscillating part consisted of a long, stainless-steel rod (length: $0.92 \mathrm{~m}$, mass: $M_{R}=800 \times \mathrm{g}$ ) with, at one end, a spherical steel mass (radius: $90 \mathrm{~mm}$, mass: $M_{S}=3004 \mathrm{~g}$ ). To minimize friction during the oscillations, the other end of the rod was free to rotate on a horizontal axis via a ball bearing. The sphere was maintained at the starting position by an electromagnet and could be released with a remote-controlled switch. To remain consistent with the model, we determined that a good 'small' starting vertical angle was $15^{\circ}$ with zero initial angular velocity. A starting angle of $10^{\circ}$ was also tested. These starting angles were accurately measured $\left( \pm 0.05^{\circ}\right)$ using a protractor fixed on the rotational axis. The force components along the $x, y$ and $z$ axes were recorded at a sampling frequency of $500 \mathrm{~Hz}$ for a maximum of $10 \mathrm{~s}$ to avoid attenuation due to friction.

A 2D mathematical model based on the forces equations developed by Fairburn et al. [29] was used to calculate $W_{\text {EXT. }}$ Briefly, $W_{\text {EXT }}$ was expressed as the integral on time of the power exerted by the vertical and horizontal forces (see supplementary material).

\subsubsection{Physical exercise in healthy subjects}

Ten volunteers from the Center des Sciences du Goût et de l'Alimentation ( 5 men, 5 women; mean body mass index: $22.1 \pm 1.9 \mathrm{~kg} \mathrm{~m}^{-2}$; mean age: $30.7 \pm 7.6$ years) performed 10 squats from a standing position. Inclusion criteria were men or women aged from 18 to 65 years old, without symptomatic musculoskeletal, locomotor and neurologic diseases and able to understand the procedures. For the mathematical model against which the calculated $W_{\text {EXT }}$ values were compared, we considered that the exercises induced only a vertical CoM displacement. $W_{\mathrm{EXT}}$ was therefore calculated as follows:

\section{$W=2 n \cdot m g h$}

where $n$ was the number of squats, $m$ the subject's body mass, $g$ the gravitational acceleration and $h$ the height of the CoM vertical displacement.

During the recording period $(\approx 45 \mathrm{~min})$, indirect calorimetry measurements were obtained. Expired gasses were collected 
through a mouthpiece and analyzed in real time and for each respiratory cycle using an open-circuit system (Vmax Spectra 29S, Sensormedics Corp., Yorba Linda, CA, USA). The exercise was preceded by a 10-15 min resting period in a reclining position, during which baseline parameters were recorded. Each exercise was followed by a recovery period $(10-15 \mathrm{~min})$ in a reclining position until the baseline values were noted. EE was calculated using the respiratory quotient as recommended [30]. Work efficiency for each exercise was calculated as the ratio between $W_{\mathrm{EXT}}$ and the increment of EE above the baseline values.

\subsection{Medical applications and test-retest reliability}

$\mathrm{W}_{\mathrm{EXT}}$ was also evaluated in 8 Parkinsonian patients, recruited from the Neurology department of Dijon University Hospital. Patients had been on treatment for at least 6 months, none had a history of falls in the previous year or symptomatic musculoskeletal diseases and all were able to understand the procedures. Ten healthy subjects with no current disease or locomotor disability or ongoing treatment served as controls (see Table 1 for patients' and controls' characteristics). All participants first had a rest period in the sitting position for baseline values $(\approx 5 \mathrm{~min})$ followed by the TUG [21,22] and then another resting period ( $\approx 10 \mathrm{~min})$. No instructions regarding time for the TUG (length identical for all participants) were given. Indirect calorimetry measurements were made throughout the recording $(\approx 20 \mathrm{~min})$, as reported previously.

Fifteen of the participants ( 9 healthy controls and 6 patients) also performed the TUG twice to evaluate the reliability of the measurements.

The protocol was approved by the Burgundy Ethics Committee, and written informed consent was obtained from each participant (healthy subjects and parkinsonian patients).

\subsection{Statistical analysis}

Values of the measured and computerized parameters are expressed as means \pm SD. Values from the theoretical model of the pendulum and measured values were compared using the average root-mean-square error (RMSE) and the normalized root-meansquare error (NRMSE) for the vertical $\left(F_{v}\right)$ and horizontal $\left(F_{h}\right)$ forces. In

Table 1

Characteristics of the 8 Parkinsonian patients and the 10 healthy subjects.

\begin{tabular}{|c|c|c|c|c|c|c|c|c|c|}
\hline Gender & $\begin{array}{l}\text { Age } \\
\text { (yrs.) }\end{array}$ & $\begin{array}{l}\text { BMI } \\
\left(\mathrm{kg} \mathrm{m}^{-2}\right)\end{array}$ & $\begin{array}{l}\text { Disease } \\
\text { Duration } \\
\text { (yrs.) }\end{array}$ & $\begin{array}{l}\text { UPDRS } \\
(/ 108)\end{array}$ & $\begin{array}{l}\text { MMS } \\
\text { score } \\
(/ 30)\end{array}$ & $\begin{array}{l}\text { Walking } \\
\text { with } \\
\text { stick }\end{array}$ & Medical history & $\begin{array}{l}\text { Antiparkinsonian } \\
\text { treatment }\end{array}$ & Other Treatments \\
\hline \multicolumn{10}{|c|}{ Parkinsonian patients $(n=8)$} \\
\hline M & 66 & 26.57 & 7 & 38 & 30 & Yes & $\begin{array}{l}\text { Thoracic } \\
\text { vertebroplasty }\end{array}$ & $\begin{array}{l}\text { Levodopa } 150 \mathrm{mg} \mathrm{3/d;} \\
\text { Levodopa } 100 \mathrm{mg} \mathrm{2/d}\end{array}$ & $\begin{array}{l}\text { Baclofen; Atorvastatin; } \\
\text { Aspirin }\end{array}$ \\
\hline $\mathrm{F}$ & 76 & 20.96 & 3 & 76 & 27 & Yes & $\begin{array}{l}\text { HBP; Dyslipidaemia; } \\
\text { Depressive syndrome }\end{array}$ & Levodopa $62.5 \mathrm{mg} \mathrm{3/d}$ & $\begin{array}{l}\text { Bromazepam; } \\
\text { Omeprazole; } \\
\text { Escitalopram; } \\
\text { Hydroxyzine; } \\
\text { Valsartan; } \\
\text { Hydrochlorothiazide; } \\
\text { Trospium chloride }\end{array}$ \\
\hline M & 80 & 18.34 & 4 & 10 & 30 & No & $\begin{array}{l}\text { Prostate adenoma; } \\
\text { Mitral valvulopathy; } \\
\text { Inflammatory } \\
\text { rheumatism } \\
\text { Depressive syndrome }\end{array}$ & Levodopa $62.5 \mathrm{mg} \mathrm{3/d}$ & $\begin{array}{l}\text { Diltiazem; Flecainide; } \\
\text { Lisinopril; } \\
\text { Cyproterone; } \\
\text { Imipramine; } \\
\text { Methotrexate; } \\
\text { Fluindione; } \\
\text { Alendronate }\end{array}$ \\
\hline M & 71 & 40.82 & 1 & 74 & 22 & Yes & $\begin{array}{l}\text { HBP; Type } 2 \text { diabetes; } \\
\text { Atrial fibrillation; } \\
\text { Obesity; Heart failure; } \\
\text { Subdural hematoma }\end{array}$ & Levodopa $125 \mathrm{mg} \mathrm{3/d}$ & $\begin{array}{l}\text { Furosemide; } \\
\text { Fluindione; } \\
\text { Perindopril; } \\
\text { Escitalopram; } \\
\text { Spironolactone; } \\
\text { Zolpidem; Lamotrigine }\end{array}$ \\
\hline $\mathrm{F}$ & 56 & 16.82 & 2 & 20 & 28 & Yes & $\begin{array}{l}\text { HBP; Type } 2 \text { diabetes; } \\
\text { Active smoking }\end{array}$ & No & $\begin{array}{l}\text { Amlodipine; } \\
\text { Telmisartan }\end{array}$ \\
\hline M & 61 & 31.51 & 8 & 35 & 30 & No & $\begin{array}{l}\text { Appendectomy; } \\
\text { Dyslipidaemia; Active } \\
\text { smoking; Depressive } \\
\text { syndrome }\end{array}$ & $\begin{array}{l}\text { Levodopa } 125 \mathrm{mg} \mathrm{3/d;} \\
\text { Ropinirole } 6 \mathrm{mg} \mathrm{3/d}\end{array}$ & $\begin{array}{l}\text { Domperidone; } \\
\text { Mirtazapine; } \\
\text { Esomeprazole }\end{array}$ \\
\hline M & 84 & 21.26 & 3 & 25 & 30 & No & $\begin{array}{l}\text { HBP; Prostate } \\
\text { adenoma; Left } \\
\text { hydronephrosis; } \\
\text { Depressive syndrome }\end{array}$ & Levodopa $125 \mathrm{mg}$ 3/d & $\begin{array}{l}\text { Aspirin; } \\
\text { Hydrochlorothiazide; } \\
\text { Tianeptine; } \\
\text { Tamsulosin }\end{array}$ \\
\hline M & 75 & 24.33 & 11 & 56 & 28 & Yes & $\begin{array}{l}\text { Prostate adenoma; } \\
\text { Dupuytren disease; } \\
\text { Pyelonephritis and } \\
\text { septicaemia }\end{array}$ & $\begin{array}{l}\text { Levodopa } 250 \mathrm{mg} \mathrm{5/d;} \\
\text { Levodopa } 125 \mathrm{mg} \mathrm{LP} 2 / \mathrm{d} \text {; } \\
\text { Ropinirole } 1 \mathrm{mg} \mathrm{5/d;} \\
\text { Entacapone } 200 \mathrm{mg} \mathrm{4/d}\end{array}$ & $\begin{array}{l}\text { Alprazolam; } \\
\text { Omeprazole; } \\
\text { Finasteride; } \\
\text { Tamsulosin; } \\
\text { Hydroxyzine; } \\
\text { Oxybutynin }\end{array}$ \\
\hline $6 \mathrm{M} / 2 \mathrm{~F}$ & $71 \pm 10$ & $25.1 \pm 7.9$ & $5 \pm 3$ & $42 \pm 25$ & $28 \pm 3$ & & & & \\
\hline \multicolumn{10}{|c|}{ Healthy subjects $(n=10)$} \\
\hline $7 \mathrm{M} / 3 \mathrm{~F}$ & $53 \pm 18$ & $24.2 \pm 2.2$ & & & & & & & \\
\hline
\end{tabular}

Gender: M for Male, F for Female. BMI: Body Mass Index. HBP: High Blood Pressure.

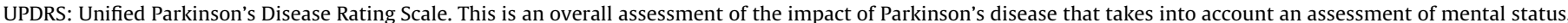

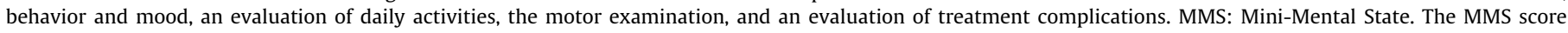
evaluates cognitive function and memory. 
fact, the mean squared error (MSE) of an estimator is one way to quantify the difference between values implied by an estimator and the true values of the quantity that is estimated. In analogy to the standard deviation, taking the square root of the MSE yields the RMSE, which has the same units as the quantity that is estimated; for an unbiased estimator, the RMSE is the square root of the variance. The NRMSE is the RMSE divided by the range $F_{v}$ of the observed values. Lower values indicate less residual variance. Differences between the human sessions were analyzed using Student's t-test. Reliability of the TUG was assessed by the two-way random effect with a single measure of absolute agreement: the Intraclass Correlation Coefficient $\left(\operatorname{ICC}_{(2,1)}\right)[31]$. Analyses were conducted using SigmaStat software (version 3.1, Systat Software Inc., Richmond, CA, USA). Statistical significance was set at $P<0.05$.

\section{Results}

\subsection{Verification of $\mathrm{W}_{E X T}$ calculations with the pendulum}

Over 10 trials, results showed that the NRMSE in the theoretical model was low for the horizontal forces $(2.3 \%$ and $2.5 \%$, respectively for the $10^{\circ}$ and the $15^{\circ}$ initial angles $\alpha_{0}$ ) and a little higher for the vertical forces $\left(8.1 \%\right.$ and $6.1 \%$, for $\alpha_{0}$ of $10^{\circ}$ and $15^{\circ}$ ). In contrast, the accuracy (MAE) for the vertical forces $(0.157 \mathrm{~N}$ and $0.203 \mathrm{~N}$ for $\alpha_{0}$ of $10^{\circ}$ and $15^{\circ}$ ) was better than for the horizontal ones $\left(0.224 \mathrm{~N}\right.$ and $0.2314 \mathrm{~N}$ for $\alpha_{0}$ of $10^{\circ}$ and $\left.15^{\circ}\right)$.

The average $W_{\text {EXT }}\left(W_{v}\right.$ and $\left.W_{h}\right)$, RMSE and NRMSE as well as the average of the MAE are indicated in Table 2. Results showed that the measured work was lower (respectively 16.5 and $26.1 \%$ for the vertical and horizontal components) than the theoretical work.

\subsection{Verification of $\mathrm{W}_{E X T}$ calculations with physical exercise in healthy subjects}

The average $W_{\text {EXT }}$ during the stand-squat exercises was $0.4 \%$ lower than the theoretical work $(1.93 \pm 0.36$ vs.1.98 \pm $\left.0.33 \mathrm{kcal} \mathrm{min}^{-1}\right)$. After measurements of total EE $(6.00 \pm 1.11 \mathrm{kcal}$ $\left.\min ^{-1}\right)$, the efficiency of the mechanical work was $32.2 \%$.

\subsection{Measurements of $\mathrm{W}_{E X T}$ in Parkinsonian patients}

$W_{\text {EXT }}$ during the TUG was non-significantly higher in Parkinsonian patients than in healthy subjects $(+46 \%, P=0.16$, Table 3$)$. In contrast, total $\mathrm{EE}$ and exercise duration were higher in patients than in healthy subjects (respectively, $+157 \%$ and $+442 \%$, $P<0.001$ for both). Therefore, the mechanical work efficiency and the amount of mechanical work performed per second were lower in patients (respectively, $-48 \%$ and $-89 \%, P<0.01$ for both).

Knowing that Parkinsonian patients have small movements with tremors, which contrasts with the high amplitude movements of healthy subjects, Fig. 1A represents the participants' $W_{\text {EXT }}$ according to their "activity rate" (corresponding to the variance in the acceleration of their CoM). The distribution of patients is clearly different from that of healthy subjects. On another aspect, it is well known that mechanical work is related to the mass of the subjects, which is clear in Fig. 1B. $W_{\text {EXT }}$ related to BMI was higher in patients than in healthy subjects $(P<0.01)$ but, in contrast, $W_{\text {EXT }}$ per second was lower in patients than in healthy subjects $(P<0.001)$. Total EE did not differ between the groups.

When the TUG was performed twice, there was no significant difference between the first and the second test for $\mathrm{W}_{\mathrm{EXT}}$, duration of exercise and total EE (respectively, during the 2nd test, $-2 \%$, $-14 \%$ and $+4 \%$ ).
Table 2

Comparison of the measured mechanical work ( $\left.W_{\mathrm{EXT}}\right)$ performed by the pendulum to the theoretical work.

\begin{tabular}{lcc}
\hline & $W_{\boldsymbol{v}}$ & $W_{h}$ \\
\hline Measured $W_{\text {EXT }}(\mathrm{J})$ & $2.28 \pm 0.06$ & $1.84 \pm 0.01$ \\
Theoretical work $(\mathrm{J})$ & 2.73 & 2.49 \\
RMSE $(\mathrm{J})$ & 0.450 & 0.650 \\
NRMSE $(\%)$ & 19.7 & 35.3 \\
MAE $(\mathrm{J})$ & 0.203 & 0.423 \\
\hline
\end{tabular}

Vertical $\left(W_{v}\right)$ and horizontal $\left(W_{h}\right)$ measured $W_{\text {EXT }}$ (Joule) of the pendulum compared with the theoretical mechanical work as well as the root-mean-square error (RMSE), the normalized root-mean-square error (NRMSE) and the mean arithmetical error (MAE) for these parameters. Initial angle $\left(\alpha_{0}\right)$ was $10^{\circ}$.

Table 3

External mechanical work and total energy expenditure measured simultaneously either by the force-platform or by indirect calorimetry, in eight Parkinsonian patients and in ten healthy subjects during a timed "get-up and go" test.

\begin{tabular}{lllll}
\hline & $\begin{array}{l}\text { Measured } \\
\text { mechanical } \\
\text { work (kcal) }\end{array}$ & $\begin{array}{l}\text { Total energy } \\
\text { expenditure } \\
\text { (kcal) }\end{array}$ & $\begin{array}{l}\text { Exercise } \\
\text { duration (s) }\end{array}$ & $\begin{array}{l}\text { Mechanical } \\
\text { work efficiency } \\
(\%)\end{array}$ \\
\hline $\begin{array}{c}\text { Parkinsonian } \\
\text { patients } \\
(n=8)\end{array}$ & $0.299 \pm 0.161$ & $2.72 \pm 1.15$ & $88 \pm 56$ & $11 \pm 4$ \\
$\begin{array}{c}\text { Healthy } \\
\text { subjects } \\
(n=10)\end{array}$ & $0.205 \pm 0.036$ & $1.06 \pm 0.51^{* * *}$ & $16 \pm 6^{* * *}$ & $22 \pm 7^{* *}$ \\
\hline
\end{tabular}

Mechanical work efficiency was calculated as the ratio of these variables. ${ }^{* *}$ and ${ }^{* * *}$ indicate significant differences $(P<0.01$ and $P<0.001)$ according to Student's $t$-test between the groups.
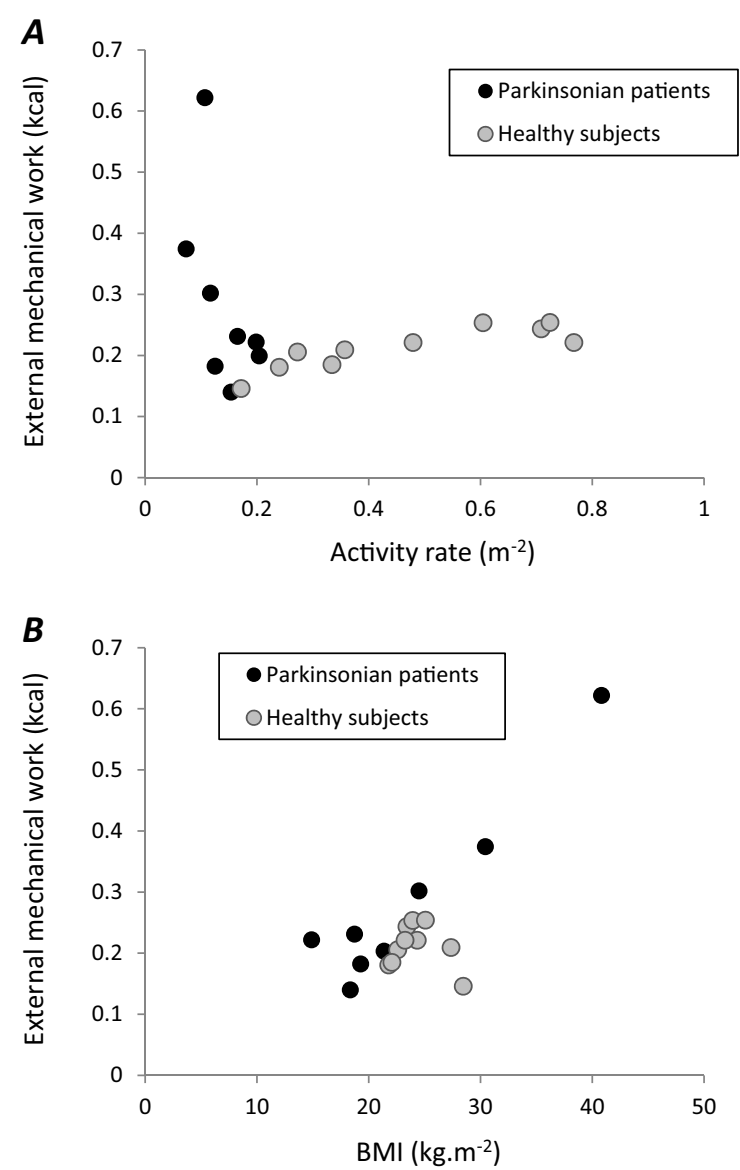

Fig. 1. External mechanical work (kcal) measured in eight Parkinsonian patients (black circles) and ten healthy subjects (gray circles) during the timed "get-up and go" test.

External mechanical work is expressed first with the subject's activity rate, which corresponds to the variance in the acceleration of the movement $(A)$, and then with the subject's Body Mass Index (B). 
$\boldsymbol{A}$

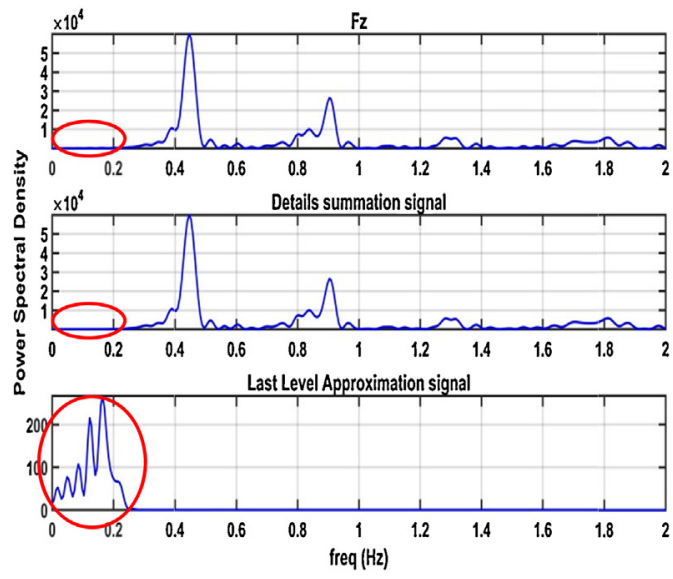

$\boldsymbol{B}$
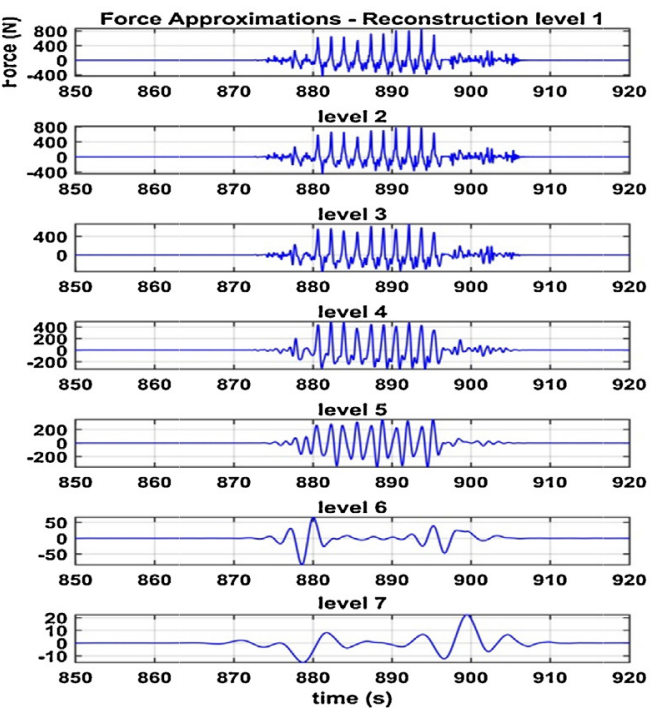

C
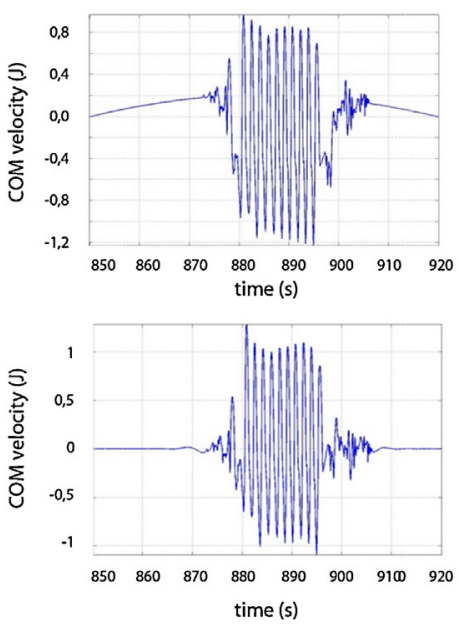
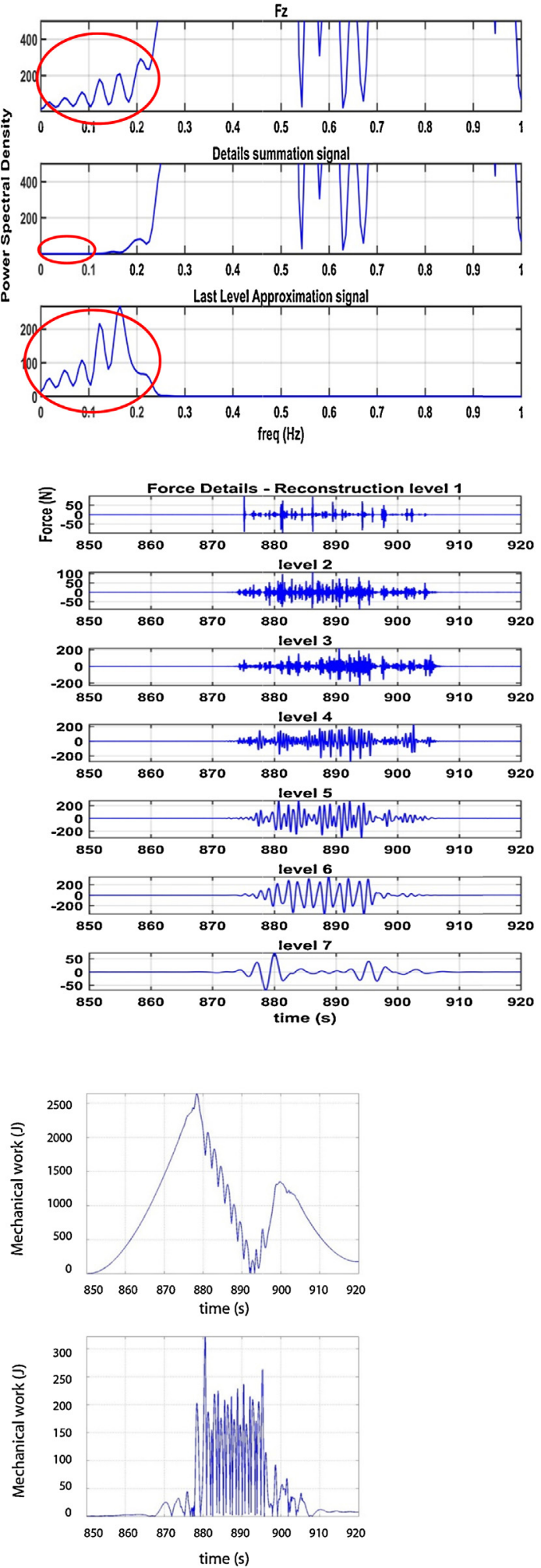

Fig. 2. Illustration of the different steps of the signal processing.

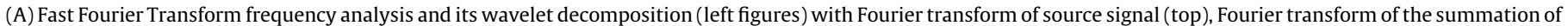

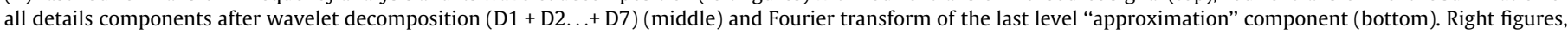
same parameters with a zoom on frequencies lower than $0.3 \mathrm{~Hz}$.

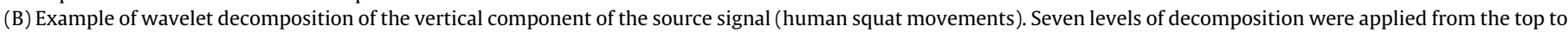

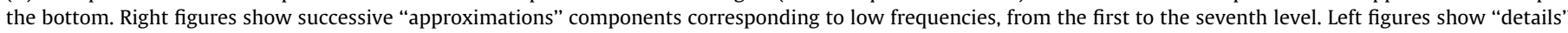
components corresponding to high frequencies.

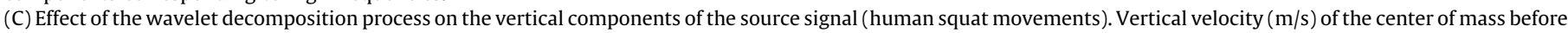

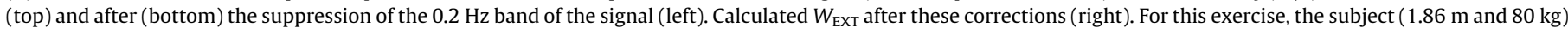
expended $2924 \mathrm{~J}$ during his displacements. 


\section{Discussion}

Even though using a large platform to measure $W_{\text {EXT }}$ has the advantage of recording ecologic situations, drift occurs when $W_{\text {EXT }}$ is calculated on data from long periods of recording. This drift was mainly due to differences between the real-time mass of the subjects and the mass used in calculations. A slight variation in this parameter with respect to the constant value of a subject's weight used in the calculations creates very low frequency components in the signal from force sensors.

Frequency analysis of the three components of the forces signal revealed that (i) the drift was due to very low frequencies of velocities $(<0.2 \mathrm{~Hz})$, and (ii) human activities inside the chamber mostly generated frequencies between 0.3 and $5 \mathrm{~Hz}$. Then, the choice of the wavelet function and order need to be made to prevent data loss (correlation between the NRMSE of the source signal and the filtered signal) and adjusted for each signal to optimize the drift correction. Fig. 2 illustrates the different steps of the signal processing with the low frequency spectrum (i.e. $<0.2 \mathrm{~Hz}$ ) before and after filtering the signal, the seven-level wavelet decomposition of the source signal with "approximations" and "details" and, the velocities and $W_{\text {EXT }}$ without and with signal processing.

After calculations, the plots and values for the forces and $W_{\mathrm{EXT}}$ during $10 \mathrm{~s}$ were close to the model both for the amplitude and frequency. The RMSE and MAE values were also very close to one another, which means that the variations in the magnitude of the errors were negligible and that the measurements obtained for the mechanical performance of the pendulum and the low forces recorded were reproducible. In fact, the variation coefficients were $2.6 \%$ for mechanical work in the vertical dimension and $0.1 \%$ in the horizontal one. Low values of the RMSE for both the vertical and horizontal components also showed that the pendulum gave values similar to those of the model and that there was never a large error between the measurements and calculations. Finally, the results showed that the sensors recorded the vertical components of the forces and $W_{\mathrm{EXT}}$ better than the horizontal ones, because the RMSE of the former was at least 1.5 times lower than that of the latter. This could be attributed to the lower friction in the vertical axis. In contrast, the NRMSE was better for the horizontal components with values that were approximately $2 \%$, whereas the value for the vertical components was $6-8 \%$. This difference could be due to the presence of fewer vibrations in the horizontal axis.

To verify the validity of $W_{\text {EXT }}$ calculations in healthy subjects, we used a squatting exercise. The results showed that the average $W_{\text {EXT }}$ from a standing position was very close to theoretical work ( $0.4 \%$ difference). We also found, in agreement with the literature $[7,32,33]$, an expected value for mechanical work efficiency of $25-30 \%$.

In some pathological conditions, it is difficult to assess the patients' $W_{\text {EXT. }}$. This information would be very interesting to study motor activity and to evaluate energy balance. This is the case for patients with Parkinson's disease. In the present study, patients with Parkinson's disease had a non-significantly higher $W_{\text {EXT }}$ $(+46 \%)$ than healthy subjects and it took them 5.5 times as long to do the exercise. The power output in patients was therefore one quarter that in healthy subjects, and their mechanical work efficiency was half that of healthy subjects. The similar $W_{\text {EXT }}$ in patients and in healthy subjects during locomotion could indicate an economy of physical activity (lack of superfluous movements) despite the increase in movements related to the disease. In support of this hypothesis, during the TUG, the "activity rate" of Parkinsonian patients was lower than that of healthy subjects. In the same way, no significant difference was found between Parkinsonian patients and control subjects for the energy cost of locomotion at a self-selected speed [34] (even though a higher energy cost of locomotion was noted when exercise intensity was imposed $[35,36])$. However, the TUG for our participants was particularly long (the cables connecting participants to the calorimeter probably lengthened the duration of the TUG by hindering walking). In a subsequent work, it could be useful to check the duration of the TUG and to evaluate $W_{\text {EXT }}$ in a greater number of Parkinsonian patients, at different stages of the disease.

In conclusion, we report a new method to calculating $W_{\text {EXT }}$ with a large force-platform. With this method, it becomes possible to evaluate patients in daily living conditions and to quantify the efficiency of movement with direct physiological and mechanical components. These aspects are of particular interest in patients with limited autonomy, in whom the quantification of functional capacities plays a key role in evaluating the stage of neuromuscular diseases, in assessing locomotor disabilities and in judging the efficacy of treatments for mobility impairments.

\section{Competing interests}

All Authors have no potential conflict of interest, financial or otherwise.

\section{Appendix A. Supplementary data}

Supplementary data associated with this article can be found, in the online version, at http://dx.doi.org/10.1016/j.gaitpost.2016.04. 013.

\section{References}

[1] Foti T, Davids JR, Bagley A. A biomechanical analysis of gait during pregnancy. J. Bone Joint Surg. Am. 2000;82:625-32.

[2] Bennett BC, Abel MF, Wolovick A, Franklin T, Allaire PE, Kerrigan DC. Center of mass movement and energy transfer during walking in children with cerebral palsy. Arch. Phys. Med. Rehabil. 2005;86:2189-94.

[3] Gottschall JS, Kram R. Energy cost and muscular activity required for leg swing during walking. J. Appl. Physiol. 2005;99:23-30.

[4] Marconi V, Hachez H, Renders A, Docquier PL, Detrembleur C. Mechanical work and energy consumption in children with cerebral palsy after single-event multilevel surgery. Gait Posture 2014;40:633-9.

[5] Van den Hecke A, Malghem C, Renders A, Detrembleur C, Palumbo S, Lejeune TM. Mechanical work, energetic cost, and gait efficiency in children with cerebral palsy. J. Pediatr. Orthop. 2007;27:643-7.

[6] Browning RC, McGowan CP, Kram R. Obesity does not increase external mechanical work per kilogram body mass during walking. J. Biomech. 2009;42:2273-8

[7] Sun M, Hill JO. A method for measuring mechanical work and work efficiency during human activities. J. Biomech. 1993;26:229-41.

[8] Chen KY, Sun M, Butler MG, Thompson T, Carlson MG. Development and validation of a measurement system for assessment of energy expenditure and physical activity in Prader-Willi syndrome. Obesity Res. 1999;7:387-94.

[9] Willems PA, Cavagna GA, Heglund NC. External, internal and total work in human locomotion. J. Exp. Biol. 1995;198:379-93.

[10] Cavagna GA. Force platforms as ergometers. J. Appl. Physiol. 1975;39:174-9.

[11] Doets HC, Vergouw D, Veeger HE, Houdijk H. Metabolic cost and mechanical work for the step-to-step transition in walking after successful total ankle arthroplasty. Hum. Mov. Sci. 2009;28:786-97.

[12] Kurz MJ, Stuberg WA, DeJong SL. Mechanical work performed by the legs of children with spastic diplegic cerebral palsy. Gait Posture 2010;31:347-50.

[13] Donelan JM, Kram R, Kuo AD. Simultaneous positive and negative external mechanical work in human walking. J. Biomech. 2002;35:117-24.

[14] Donelan JM, Kram R, Kuo AD. Mechanical work for step-to-step transitions is a major determinant of the metabolic cost of human walking. J. Exp. Biol. 2002;205:3717-27.

[15] Schepens B, Detrembleur C. Calculation of the external work done during walking in very young children. Eur. J. Appl. Physiol. 2009;107:367-73.

[16] Schepens B, Bastien GJ, Heglund NC, Willems PA. Mechanical work and muscular efficiency in walking children. J. Exp. Biol. 2004;207:587-96.

[17] Robertson DG, Fleming D. Kinetics of standing broad and vertical jumping. Can. J. Sport Sci. 1987;12:19-23.

[18] Arampatzis A, Knicker A, Metzler V, Bruggemann GP. Mechanical power in running: a comparison of different approaches. J. Biomech. 2000;33:457-63.

[19] Butler MG, Theodoro MF, Bittel DC, Donnelly JE. Energy expenditure and physical activity in Prader-Willi syndrome: comparison with obese subjects. Am. J. Med. Genet. A 2007;143:449-59. 
[20] Thureen PJ, Phillips RE, DeMarie MP, Hoffenberg A, Bronstein MN, Spedale SB, et al. Technical and methodologic considerations for performance of indirect calorimetry in ventilated and nonventilated preterm infants. Crit. Care Med. 1997;25:171-80.

[21] Mathias S, Nayak US, Isaacs B. Balance in elderly patients: the "get-up and go" test. Arch. Phys. Med. Rehabil. 1986;67:387-9.

[22] Podsiadlo D, Richardson S. The timed "Up \& Go": a test of basic functional mobility for frail elderly persons. J. Am. Geriatr. Soc. 1991;39:142-8.

[23] Lafond D, Duarte M, Prince F. Comparison of three methods to estimate the center of mass during balance assessment. J. Biomech. 2004;37:1421-6.

[24] Wachowiak MP, Rash GS, Quesada PM, Desoky AH. Wavelet-based noise removal for biomechanical signals: a comparative study. IEEE Trans. Biomed. Eng. 2000;47:360-8.

[25] S. Domone, J. Wheat, S. choppin, N. Hamilton, B. Heller, Wavelet based denoising of non-stationary kinematic signals, 30th Annual Conference of Biomechanics in Sports, Melbourne, 2012, https://ojs.ub.uni-konstanz.de/cpa/ article/viewFile/5309/4880.

[26] Ismail AR, Asfour SS. Discrete wavelet transform: a tool in smoothing kinematic data. J. Biomech. 1999;32:317-21.

[27] Vetterli M, Herley C. Wavelets and filter banks-theory and design. IEEE Trans. Signal. Process. 1992;40:2207-32.
[28] Mallat SG. A theory for multiresolution signal decomposition-the wavelet representation. IEEE Trans. Pattern Anal. Mach. Intell. 1989;11:674-93.

[29] Fairburn PS, Palmer R, Whybrow J, Fielden S, Jones S. A prototype system for testing force platform dynamic performance. Gait Posture 2000;12: 25-33.

[30] Peronnet F, Massicotte D. Table of nonprotein respiratory quotient: an update. Can. J. Sport Sci. 1991;16:23-9.

[31] Weir JP. Quantifying test-retest reliability using the intraclass correlation coefficient and the SEM. J. Strength Cond. Res. 2005;19:231-40.

[32] Brooks GA. Bioenergetics of exercising humans. Compr. Physiol. 2012;2: 537-62.

[33] Perrault H. Efficiency of movement in health and chronic disease. Clin. Invest. Med. 2006;29:117-21.

[34] Maggioni MA, Veicsteinas A, Rampichini S, Ce E, Nemni R, Riboldazzi G, et al. Energy cost of spontaneous walking in Parkinson's disease patients. Neurol. Sci. 2012;33:779-84.

[35] Christiansen CL, Schenkman ML, McFann K, Wolfe P, Kohrt WM. Walking economy in people with Parkinson's disease. Mov. Disord. 2009;24:1481-7.

[36] Pelosin E, Faelli E, Lofrano F, Avanzino L, Marinelli L, Bove M, et al. Effects of treadmill training on walking economy in Parkinson's disease: a pilot study. Neurol. Sci. 2009;30:499-504. 